\title{
PENGARUH KEPEMIMPINAN, BUDAYA ORGANISASI DAN MOTIVASI KERJA TERHADAP KINERJA PERSONIL KEPOLISIAN PADA KANTOR POLSEK SE-KABUPATEN PIDIE JAYA
}

\author{
Mahyuddin ${ }^{1)}$ dan Azhari ${ }^{*}$ )
}

${ }^{1}$ Kepala Subbagian Pembinaan Operasional Polres Pidie Jaya

2, Dosen FE Universitas Islam kebangsaan Indonesia (UNIKI)

*) email: azhari@uniki.ac.id

DOI:

https://doi.org/10.55178/idm.v2i4.219

ABSTRACT

\section{Article history}

Received:

September 11, 2021

Revised:

September 15, 2021

Accepted:

September 18, 2021

Page:

$17-27$

\section{Kata kunci:}

Leadership,

Organizational Culture,

Work Motivation,

Performance
The purpose of this research is to prove and analyze, 1) The influence of leadership on personnel performance, 2) The influence of organizational culture on personnel performance, 3) The influence of work motivation on personnel performance, and 4) The influence of leadership, organizational culture, and work motivation simultaneously on the performance of police personnel in all Pidie Jaya District Police Offices, Aceh Province. The analysis was carried out descriptively and with a Path analysis approach. The results of the descriptive study show that the response of the police personnel being studied is the perceived leadership level of what is expected by the Polri personnel at the Pidie Jaya Police office, judged by the personnel to be good, reaching 79.56 percent of expectations. Meanwhile, the assessment of aspects of organizational culture is quite good in supporting personnel performance. Personnel assessment scores on organizational culture among offices reached $73.48 \%$ and from the assessment the level of work motivation of personnel reached $76 \%$, and this is quite good, and the level of performance has reached a fairly good category, namely $74.03 \%$, although it still can. be improved again. The results of the correlation analysis between variables show that the correlation between leadership, organizational culture and work motivation on the performance of the Police personnel at the Pidie Jaya Police Office is obtained $R$ of 0.803 which explains the relationship between independent variables and dependent variables, has high closeness, and is linearly related, with The degree of relationship is 0.803 Based on quantitative analysis, using a path analysis approach, the results are: a) There is a significant influence on the aspects of leadership on the performance of Polri personnel at the Pidie Jaya Police office $(Y)$, both direct and indirect effects due to the relationship between The variables studied were 37.62 percent, $b$ ). There was a direct influence on organizational culture factors, or an indirect influence due to the causal relationship between organizational culture and leadership and work motivation on the performance of Polri personnel at the Pidie Jaya Police office, namely 11.50 percent, $c$ ). There is a significant influence on aspects of work motivation on the performance of the Police Personnel at the Pidie Jaya Police office, namely 15.51 percent, $d$ ). The amount of influence of leadership, organizational culture and work motivation on personnel performance is $64.5 \%$. While the rest (residual value) from the role of the variables not studied was $35.5 \%$. The residual value indicates that there are other factors that can affect the personnel performance variable.

\section{Pendahuluan (Introduction)}

Sumber Daya Manusia (SDM) merupakan asset dan salah satu modal dalam pembangunan, termasuk dalam suatu institusi kepolisian. Sehingga mulai dari penerimaan personil atau pegawai hingga proses penetapan pekerjaan dilakukan beberapa tahapan pembinaan, khususnya dalam softskill dan mental. Sehingga pada akhirnya tersedia SDM yang terdidik, terampil, berdisiplin, tekun dan mau bekerja keras untuk perubahan dalam kinerja individu dan sumbangsihnya pada kinerja institusi.

Personil yang tangguh dan terpercaya sangat dibutuhkan pada tubuh Kepolisian Negara Republik Indonesia (POLRI). Mengingat masih terdapat pandangan dan image yang negative pada personil Polri, baik dalam perilaku dan cara atau pendekatan mereka dalam mengayomi masyarakat sesuai motonyanya bahwa Polisi 
harus menjadi pelindung, pengayom dan pelayan masyarakat. Bentuk pengayoman diterapkan dengan memberikan pembinaan kepada warga, baik orang tua dan pemuda di wilayah rawan konflik. Sedangkan bentuk pelayanan dapat dirasakan dengan respon yang cepat polisi terhadap laporan masyarakat.

Kabupaten Pidie Jaya salah satu kabupaten baru hasil pemekaran dari kabupaten Pidie di tahun 2007. Dengan ibukota Meureudu, saat telah memiliki kantor Polres sendiri yang diresmikan tahun 2020, yang sebelum bergabung dengan Pidie. Dengan 8 (delapan) kecamatan dan 34 pemukiman serta 222 desa, berpenduduk mendekati 149 ribu tahun 2015 dan dengan laju pertumbuhan penduduk 2,15\% per tahun, maka tahun 2021 lalu diperkirakan mencapai168.500 jiwa. Sehingga diperlukan aparat kepolisian yang sigap dan berkualitas dalam menjaga kemanan dan kenyamanan masyarakat di kabupaten tersebut.

Kepolisian Resort (Polres) Pidie Jaya merupakan pelaksana tugas Kepolisian Republik Indonesia di wilayah tersebut. Yang merupakan suatu instansi kepolisian yang berada di bawah jajaran Polda Aceh, menjalankan tugas pada masyarakat di seluruh wilayah hukum yang menjadi tanggung jawabnya. Dalam menjalankan tugas-tugas utama yang diembannya maka Polres Pidie Jaya dibantu oleh keberadaan satker-satker yang berada di bawahnya.

Dalam menjalankan tugas, yang langsung berhadapan dengan masyarakat, Polisi harus siap baik mental dan kemampuan serta tanggung jawab sebagai abdi Negara. Untuk menyiapkan polisi yang handal dan dipercaya masyarakat, menjadi tugas pempimpin di institusi ini, yakni Kepala Polres setempat dan pimpinan langsung dari aparat atau personil tersebut berdinas, seperti Kapolsek dan Ketua Satker masing-masing.

Sekali lagi, penekanan pada Sumber daya manusia, sangat penting. Bahkan disebutkan sebagai kunci bagi kelangsungan suatu organisasi. Maka dari itu, pimpinan berkewajiban membina dan meningkatkan kinerja aparat dan pegawainya, akan ikut berpengaruh pada peningkatan efektivitas dan efisiensi organisasi. Sebagaimana disebutkan M. Yusuf (2015:27), kata kunci sukses, jika mampu mengelola sumber daya manusia dengan sebaik-baiknya, sebagai kekuatan yang dimiliki oleh suatu organisasi.

Masih dijumpai di beberapa tempat dan daerah, bahwa kepercayaan masyarakat atas kinerja aparar Kepolisian masih dirasakan kurang. Image negatif masih ada melekat pada aparat penegak hukum ini.

Hal ini disebabkan adanya beberap aparat termasuk oknum dalam tubuh Kepolisian bersikap perilaku belum santun, tidak terpuji dalam pelayanan. Oleh karenanya, aparat harus menyadari, bahwa keragaman budaya, suku, agama, dan etnis yang ditambah dengan pergeseran nilai-nilai luhur Pancasila dalam perikehidupan sebagian masyarakat dalam berbangsa dan bernegara menjadi potensi terciptanya konflik sosial.

Berdasarkan data dari beberapa kantor Polsek yang dilaporkan kepada Polres Pidie Jaya, terkait dengan pengungkapan kasus khususnya menyangkut kejahatan (pembunuhan, pencurian dengan kekerasan, pencurian dengan pemberatan, pencurian kendaraan bermotor dan pencurian lainya serta penyalahgunaan narkoba), terus menjadi pekerjaan rutin personil Kepolisian di Kabupaten Pidie Jaya tersebut. Tentu hal ini menjadi tantangan pada pimpinan yang memeiliki personil kepolisian, untuk lebih profesional dan memperhatikan akan kekuatan, kelemahan serta kebutuhan para anggotanya.

Di setiap Kantor Polsek Kabupaten Pidie Jaya, sebagai daerah yang baru, tentu masih menghadapi banyak kendala internal yang perlu dibenahi, apakah belum memadainya pengetahuan dan keterampilan personil beberapa Polsek di wilayah Kabupaten Pidie Jaya. Sehingga target dalam melaksanakan tugasnya masih belum optimal.

Menurut data dari Laporan Tahunan Kamtibmas Reskrim pada kantor-kantor Polsek Kabupaten Pidie Jaya di Tahun 2018 dan 2019 ini, secara umum dari sejumlah potensi Kamtibmas di wilayah hukum Polsek yang ada di Kabupaten Pidie Jaya, hanya sekitar 50 - 60 persen jenis kasus dapat ditangani dan diselesaikan pada tahun berjalan. Belum maksimalnya semua kinerja Polsek di wilayah kerja Kabupaten Pidie Jaya memberikan indikasi bahwa banyak faktor yang perlu diperhatikan oleh pimpinan Polsek dan Kapolres setempat dalam rangka meningkatkan kinerja personilnya.

Banyak indikator yang menunjukkan peningkatan kerja kantor Polsek, pengungkapan perkara merupakan salah satu ukuran dari optimalisasi kerja penyelidikan, juga pengungkapan perkara suatu keniscayaan yang segera dipastikan hasilnya, karea hal ini langsung berkaitan dengan masyarakat. Dengan hal itu akan terukur oleh masyarakat kinerja aparat Kepolisian.

Meningkatkan kinerja personil pada kantor Polsek, seperti di wilayah kerja Pidie Jaya, sudah menjadi kewajiban, dengan memperhatikan selalu faktor yang mempengaruhinya. Seperti kepemimpinan, budaya kerja, dan motivasi, juga seperti komitemen organisasi dapat diakomodasikan dengan baik dan diterima oleh semua personil di dalam suatu organisasi Polsek bersangkutan. 
Dalam kajian menajemen SDM, sudah banyak kajian teoritis dan empiris yang menjadi titik point yang harus diperhatikan. Hal yang utama dari faktor gaya kepemimpinan. Sebab hal ini langsung mengarahkan organisasi dan juga pemberian contoh perilaku terhadap para pengikut (pegawai) di dalam kemajuan dan kemunduran organisasi (Mas'ud, 2004).

Disamping itu, perkara hasil kerja akan juga banyak terkait dari factor internal pegawai tersebut, yakni yang dipastikan adalah motivasi kerjanya. Tanpa ada motivasi yang maksimal dan terus dapat dipertahankan akan berimbas penuh pada Kinerja personil. Oleh karenanya, dalam mendukung motivasi kerja personil juga difasilirasi dengan budaya organisasi yang kuat dan memberikan motivasi kerja kepada personilnya untuk berkinerja tinggi.

Berdasarkan uraian di atas peneliti melihat adanya fenomena yang menarik untuk dibahas lebih lanjut, dan berdasarkan latar belakang masalah tersebut maka penulis mengambil judul "Pengaruh fungsi kepemimpinan, budaya organisasi dan motivasi kerja terhadap kinerja personil kepolisian di seluruh Kantor Polsek se-Kabupaten Pidie Jaya"

\section{Tinjauan Literatur (Literature Review)}

\section{Pengaruh Kepemimpinan dan Budaya Organisasi terhadap Kinerja}

Kepemimpinan dan budaya organisasi dalam institusi menjadi elemen penting dalam meningkatkan motivasi kerja pegawai, yang bermuara pada peningkatan kinerja individu dan institusi (Taba Iskandar, 2004).

Dan sebaliknya dengan budaya yang telah tertanam disepakati semua pihak, dan dijalankan dalam kehidupan organisasi atau isntitusi kepolisian misalnya, akan mempengaruhi efektivitas seorang pemimpin. Karena budaya organisasi mengungkapkan nilai-nilai inti yang dianut bersama oleh mayoritas anggota organisasi. Budaya organisasi dapat memberikan stabilitas bagi suatu organisasi, tetapi juga dapat menjadi menghambat penghambat dalam melakukan perubahan. Disini, maknanya ada hubungan timbal balik antara peran pemimpin mengayomi dan menjaga budaya tetap eksis, dan dengan nilai-nilai dan sistem makna bersama yang dianut oleh anggota-anggota yang membedakan organisasi itu dari organisasiorganisasi lain, akan sangat terkait dengan pemimpin.

Peran pemimpin dalam hal ini adalah membangun tim, menciptakan kesatuan, dan menyelesaikan perselisihan di tingkat kelompok, dan pada akhirnya pemimpin membangun budaya dan menciptakan perubahan dalam organisasi (Melers et.al, 1998, dalam Kreitner dan Kinicki, 2010). Sehingga dapat dikatakan, budaya pada hakekatnya pondasi bagi suatu organisasi untuk mengokohkan dan menopang jalannya organisasi.

Suryo (2010), Ogbonna dan Harris (2000). dalam penelitiannya menemukan bahwa gaya kepemimpinan transformasional berpengaruh signifikan terhadap variabel budaya organisasional. Karena pemimpin dapat membangun tim kerja, menciptakan kesatuan, dan menyelesaikan perselisihan di tingkat kelompok, dan pada akhirnya pemimpin membangun budaya dan menciptakan perubahan dalam organisasi (Melers et.al, 1998, dalam Kreitner dan Kinicki, 2010).

Oleh karenanya, sesungguhnya keberadaan Kepala Kepolisian di daerah, apakah Kapolres atau Kapolsek harus memiliki kemampuan dan memaksimalkan peran dan fungsi dalam membina personil yang di pimpinnya, juga didasarkan budaya di lingkungan kepolisian yang sudah baku dan kuat, dalam mencapai kinerja kerja.

Dengan itu, disadari hal ini penentu terciptanya hasil kerja yang optimal, maka harus didukung penuh dengan adanya pemimpin yang peduli dalam mengatur personilnya, yang pada gilirannya akan membawa hasi kerja Polres/Polsek yang produktif.

Kepemimpinan dalam kepolisian menggunakan garis komando, namun tetap berlandaskan pembinaan dan mengayomi dan menggerakkan anggota untuk terus bekerja, mengabdi kepada Negara dan beprestasi. Maknanya kepemimpinan membawa anggota untuk bekerja secara profesional dan memiliki kinerja yang tinggi sebagaimana diharapkan dalam visi Kepolisian Republik Indonesia, yakni "Terwujudnya pelayanan keamanan dan ketertiban masyarakat yang prima, tegaknya hukum dan keamanan dalam negeri yang mantap serta terjalinnya sinergi polisional yang proaktif".

Penilaian kinerja bagi anggota Kepolisian Negara Republik Indonesia dengan sistem manajemen kinerja yang diatur dalam peraturan Kepolisian Negara Republik Indonesia nomor 2 tahun 2018. Yang bertujuan dalam rangka pembinaan karir, pendidikan pengembangan, kenaikan pangkat, dan pemberian tunjangan 
kinerja. Dimana penilaiannya oleh atasan langsung. Oleh karenanya peran pimpinan sangat menentukan dalam peningkatan kinerja anggota.

Hal ini senada dengan penelitian Sani dan Maharani (2012) dan Salanova et al (2011) serta Walumbwa dan Hartnell (2010), bahwa terdapat hubungan yang signifikans dan positif antara Kepemimpinan dengan kinerja individu (pegawai).

Setiap individu dalam sebuah organisasi memiliki budaya yang berbeda dan para karyawan pada awalnya mencoba menyesuaikan diri kepada norma-norma dan nilai-nilai dari organisasi. Mengadopsi budaya organisasi tersebut sangat membantu bagi para karyawan untuk melakukan pekerjaannya secara efektif dan efisien.

Secara empiris, sudah ada temuan pembukian hal ini seperti penelitian Kottter dan Heskett dalam Sopiah (2008:177), penelitian Shahzad et. al., (2012: 975-985). Kesemuanya menyimpulkan ada kaitan besar budaya organisasi terhadap kinerja karyawan.

Membangun budaya organisasi dan pemberdayaan polisi di Indonesia dapat mendorong terwujudnya kinerja Polri yang ditunjukkan oleh komitmen terhadap organisasi melalui tiga pendekatan yang terintegrasi yaitu pendekatan struktural, instrumental dan kultural. Hal inilah yang menjadi landasan menurunkannya dalam tigas pokok dan fungsi Kepolisian.

\section{Pengaruh Kepemimpinan dan Motivasi Kerja terhadap Kinerja}

Dalam proses kepemimpinan, motivasi merupakan sesuatu yang esensial dalam kepemimpinan, karena memimpin pada dasarnya ikut andil dalam memotivasi bawahannya. Seorang pemimpin harus bekerja bersama-sama dengan orang lain atau bawahannya, untuk itu diperlukan kemampuan memberikan motivasi kepada bawahan.

Keberhasilan seorang pemimpin dalam menggerakkan orang lain untuk mencapai tujuan yang telah ditetapkan sangat bergantung kepada kewibawaan, khususnya dalam ranah kemampuan pemimpin menciptakan motivasi dalam setiap orang bawahan, kolega maupun atasan pemimpin itu sendiri. Maka fungsi kepemimpinan saling berhubungan dengan motivasi kerja (Wahjosumidjo,1984).

Dengan demikian, secara fungsional dan praktis keorganisasian, terdapat kaitan kepemimpinan sebagai individu dan tugasnya memotivasi pegawai secara operasional tugas pada bawahannya. Sehingga, jika para bawahannya memiliki motivasi yang tinggi dan tekad yang besar untuk bekerja secara baik akan memudahkan pimpinan mengkoordinir potensi yang ada. Karena memiliki motivasi untuk berprestasi.

Hasil penelitian Kustrianingsih Maria Magdalena Minarsih, Leonardo Budi Hasiholan (2014) yang dikutip oleh Win dan Faisal (2019;32), menunjukkan bahwa motivasi kerja berpengaruh positif dan signifikan terhadap kinerja karyawan. Jadi motivasi kerja merupakan salah satu upaya yang dapat meningkatkan kinerja. Hal ini merupakan wujud perhatian dan pengakuan pimpinan kepada pegawai yang menunjukan kemampuan kerja, kerajinan, dan kepatuhan serta disiplin kerja (Nova dan Megasari Gusandra Saragih, 2016:30).

Berdasarkan hal diatas dapat diketahui bahwa motivasi kerja mempengaruhi atas pencapaian kinerja personil kepolisian. Dengan demikian menunjukkan bahwa terdapat keterkaitan antara motivasi kerja dengan usaha pencapaian kinerja personil kepolisian secara maksimal.

\section{Metode Penelitian (Methodology)}

\section{a. Metode dan Variabel Penelitian}

Penelitian yang dilakukan pada anggota atau personil Kepolisian di Kantor Polsek se-Kabupaten Pidie Jaya, Provinsi Aceh, melalui cara deskriptif dan asosiatif kuantitatif. Sanpel obejk penelitianmelalui random sampling.

Metode asosiatif kuantitatif adalah analisis hubungan antar variabel dimana data berupa angka atau numerik. Sugiyono $(2011$ :7) menambahkan bahwa metode penelitian kuantitatif dapat diartikan sebagai metode penelitian yang berlandaskan pada filsafat positivisme digunakan untuk meneliti pada populasi atau sampel tertentu.

Teknik pengambilan sampel pada umumnya dilakukan secara acak (random sampling), pengumpulan data menggunakan instrumen penelitian, analisis data bersifat kuantitatif dengan alat bantu statistik, dengan tujuan untuk menguji hipotesis yang telah ditetapkan. 
Variabel penelitian terdiri atas independent variable, yakni Kepemimpinan $\left(\mathrm{X}_{1}\right)$, Budaya Organisasi $\left(\mathrm{X}_{2}\right)$, dan Motivasi kerja $\left(\mathrm{X}_{3}\right)$. Dan dependent variable, yakni Kinerja personil Kepolisian (Y). Adapun variabel, dimensi dan indikator pengukurnya dinyatakan berikut ini.

Tabel 1. Operasional Variabel Penelitian

\begin{tabular}{|c|c|}
\hline Variabel & Indikator \\
\hline $\begin{array}{l}\text { Kepemimpinan } \\
\left(\mathrm{X}_{1}\right) \\
\text { Sumber: } \\
\text { Siagian (1999) }\end{array}$ & $\begin{array}{ll}\text { 1. } & \text { Fungsi Instruktif } \\
\text { 2. } & \text { Fungsi Konsultatif } \\
\text { 3. } & \text { Fungsi Partisipasi } \\
\text { 4. } & \text { Fungsi Delegasi } \\
\text { 5. } & \text { Fungsi Pengendalian }\end{array}$ \\
\hline $\begin{array}{c}\text { Budaya Organisasi } \\
\text { (X2) } \\
\text { Sumber: } \\
\text { Robbins dalam Sembiring (2012:41) }\end{array}$ & $\begin{array}{l}\text { 1. Inisiatif } \\
\text { 2. Pengarahan } \\
\text { 3. Integritas } \\
\text { 4. Kontrol } \\
\text { 5. Pola Komunikasi }\end{array}$ \\
\hline $\begin{array}{c}\text { Motivasi Kerja } \\
\text { (X3) } \\
\text { Sumber: } \\
\text { Pandji Anoraga (2012) }\end{array}$ & $\begin{array}{l}\text { Kebutuhan: } \\
\text { 1. Fisiologis } \\
\text { 2. Keamanan } \\
\text { 3. Sosial } \\
\text { 4. Penghargaan } \\
\text { 5. Aktualisasi Diri }\end{array}$ \\
\hline $\begin{array}{c}\text { Kinerja } \\
(\mathrm{Y}) \\
\text { Sumber: } \\
\text { Samsudin (2005) }\end{array}$ & $\begin{array}{ll}\text { 1. } & \text { Kehadiran } \\
\text { 2. Loyalitas } \\
\text { 3. Kualitas Kerja } \\
\text { 4. Kuantitas Kerja } \\
\text { 5. Inisiatif } \\
\text { 6. Kepemimpinan }\end{array}$ \\
\hline
\end{tabular}

\section{b. Populasi dan Sampel Penelitian}

Populasi dalam penelitian ini adalah seluruh personil (anggota) Polisi pada Polsek se-Kabupaten Pidie Jaya yang berjumlah 81 orang. Karena jumlahnya terbatas, maka keseluruhan angggota populasi dijadikan sampel, yakni 81 orang polisi, yang disebut dengan sampel jenuh, atau sampel total.

\section{c. Alat Analisis}

Metode dan alat analisis dalam rangka menjawab permasalahan dan tujuan yang dicapai dilakukan dengan pendekatan model secara statistik, yang dapat mengukur pengaruh antar variable eksogen terhadap variable endogen, dimana terdapat dugaan antar variable eksogen memiliki kausalitas. Oleh karenanya digunakan Analisis jalur (Path Analysis).

Analisis jalur ialah suatu teknik untuk menganalisis hubungan sebab-akibat yang terjadi pada regresi berganda jika variabel bebasnya mempengaruhi variabel tergantungnya tidak hanya secara langsung, tetapi juga secara tidak langsung” (Robert D. Rutherford, 1993, dalam Marwan Hamid, dkk; 2019:10).

Dengan pendekatan model jalur, analisis mengikuti jalur hubungan kausal variabel independent (eksogen) memberikan dampak langsung dan tidak langsung terhadap variabel terikat (endogen). Untuk dapat menggunakan alat analisis ini, dipastikan data memiliki skala ukur minimal interval. Juga syarat statistik regresi dan analisis jalur, terpenuhinya semua asumsi klasik, yakni normalitas, heterosidasitas, multikolinieritas.

\section{Hasil dan Pembahasan (Results and Discussion)}

\section{a. Karakteristik Responden}

Jumlah subjek penelitian adalah 81 personil Polri pada lingkup kerja Kapolres Pidie Jaya, Aceh. Subjek penelitian adalah semua personil yang memiliki otoritas pada Kapolres Pidie Jaya yang dibawahi oleh seorang pimpinan yaitu Kapolres.

Subjek penelitian juga adalah seluruh Kapolsek yang bekerja untuk beberapa kecamatan di lingkungan kerja Kabupaten Pidie Jaya, seperti Kapolsek Bandar Baru, Kapolsek Panteraja, Kapolsek Trienggading, Kapolsek Meureudu, Kapolsek Meurah Dua dan Kapolsek Ulim , Kapolsek Jangka Buya dan Kapolsek Bandar Dua. Dari semua personil Polri tersebut yakni 81 orang, semua adalah anggota POLRI yang 
beragaram Islam dan usia rata- rata 35 - 45 tahun. Dan pendidikan umumnya SLTA, dan sebagian Sarjana (S1).

\section{b. Hasil analisis Deskriptif}

Berdasarkan hasil kuesioner yang telah teruji validitas dan reliabilitasnya dari 81 personil kepolisian pada Kapolres Pidie Jaya, Aceh, diperoleh jawaban terhadap variabel yang diteliti sebagai berikut.

Tabel 2.

Deskripsi Penilaian Personil tentang Variabel Penelitian

\begin{tabular}{|l|c|c|c|c|c|c|}
\hline \multirow{2}{*}{ Variabel } & \multicolumn{5}{c|}{ Jumlah \& } & \multirow{2}{*}{$\begin{array}{c}\text { Skor Pencapaian \& } \\
\text { Persentase Pencapaian }\end{array}$} \\
\cline { 2 - 7 } & STS & TS & KS & S & SS & 1611 \\
\hline \multirow{2}{*}{ Kepemimpinan : 5 pernyataan } & 0 & 22 & 101 & 146 & 136 & 79.56 \\
\cline { 2 - 8 } & 0.00 & 5.43 & 24.94 & 36.05 & 33.58 & 1488 \\
\hline \multirow{2}{*}{ Budaya organisasi : 5 pernyataan } & 0 & 31 & 144 & 153 & 76 & 73.48 \\
\cline { 2 - 8 } & 0.00 & 7.65 & 35.56 & 37.78 & 18.77 & 1539 \\
\hline \multirow{2}{*}{ Motivasi kerja : 5 pernyataan } & 0 & 42 & 121 & 118 & 124 & 76.00 \\
\cline { 2 - 8 } & 0.00 & 10.37 & 29.88 & 29.14 & 30.62 & 1799 \\
\hline \multirow{2}{*}{ Kinerja : 6 pernyataan } & 0 & 44 & 155 & 189 & 98 & 74.03 \\
\cline { 2 - 7 }
\end{tabular}

Sumber : Hasil Peneltian, 2021

Keterangan : SS (Sangat Setuju), S (Setuju), KS (Kurang setuju), TS (Tidak Setuju) STS (Sangat tidak setuju)

Skor pencapaian setiap variabel diperoleh dari perkalian bobot setiap jawaban terhadap jumlah jawaban responden. Dan persentase Pencapaian adalah perbandingan dari skor pencapaian penelitian dengan skor idealnya, dimana skor ideal adalah dengan bobot $\mathrm{SS}=5$.

Dengan jumlah jawaban 2025, sehingga skor ideal variable kepemimpinan adalah 5 x $405=2025$. Sedangkan skor pencapaian 1611, maka persentase pencapaian aspek kepemimpinan yang diharapkan adalah $=(1611 / 2025) \mathrm{x} 100 \%=79,56 \%$. Dan hasil ini menunjukkan sudah cukup baik.

Dengan cara yang sama juga diketahui skor pencapaian variable lain yakni:

- Variabel Budaya organisasi, termasuk cukup dalam kinerja personil. Skor penilaian personil atas budaya organisasi di kantor polres/polsek mencapai 73,48\%

- Variabel Motivasi kerja, faktor penting juga mendukung komitmen personil untuk meningkatkan kinerjanya. Menurut penilaian atas personil, tingkat motivasi kerjanya mencapai $76 \%$, dan hal ini termasuk cukup baik, walaupun belum optimal.

- Terakhir ukuran tingkat Kinerja sudah mencapai kategori cukup baik, yakni 74,03 \%, walaupun masih bisa ditingkatkan lagi.

\section{c. Uji Asumsi Klasik}

\section{1). Uji Normalitas}

Uji Normalitas melalui grafik kurva normal. jika data menyebar normal di sekitar garis diagonal dan mengikuti arah garis diagonal, maka model regresi memenuhi asumsi normalitas (Santoso, 2009:342, Sugiyono, 2003). Maka hasil gambar 1 menunjukkan asumsi normalitas dipenuhi.

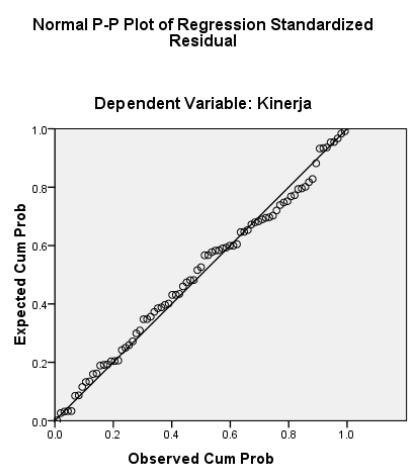

Gambar 1. Uji Normalitas 


\section{2). Uji Multikolinearitas}

Uji Multikolinearitas ditunjukkan dalam tabel 2 berikut:

Tabel 3. Hasil Uji Multikolinearitas

\begin{tabular}{|c|c|c|c|c|c|}
\hline \multirow[b]{2}{*}{ Model } & \multirow{2}{*}{\begin{tabular}{|c|} 
Standardized Coefficients \\
Beta \\
\end{tabular}} & \multirow[b]{2}{*}{$\mathrm{t}$} & \multirow[b]{2}{*}{ Sig. } & \multicolumn{2}{|c|}{ Collinearity Statistics } \\
\hline & & & & Tolerance & VIF \\
\hline (Constant) & & -.123 & .903 & & \\
\hline Kepemimpinan & .506 & 5.881 & .000 & .623 & 1.605 \\
\hline Budaya Organisasi & .192 & 2.220 & .029 & .619 & 1.615 \\
\hline Motivasi Kerja & .247 & 2.838 & .006 & .611 & 1.638 \\
\hline
\end{tabular}

Sumber : Hasil Peneltian, 2021

Nilai Variance Inflation Factor $(V I F)<10$ dan mempunyai angka Tolerance $>0$. Jadi dapat disimpulkan bahwa tidak ada multikollinieritas antar variabel bebas dalam model regresi (Santoso, 2009).

\section{3). Uji Heterokedastisitas}

Pendeteksian heterokedastisitas melalui scatterplot dengan menggunakan alat bantu SPSS diperoleh hasilnya berikut :

Scatterplot

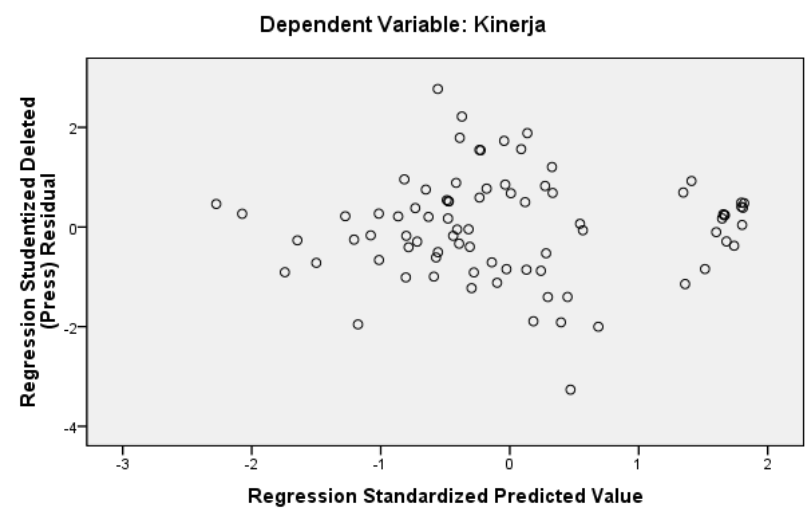

Gambar 2. Uji Heterokedastisitas

Terlihat titik-titik menyebar secara acak (random) serta tersebar di atas maupun di bawah angka 0 pada sumbu Y, sehingga tidak terjadi heterokedastisitas.

\section{d. Hasil Analisis Jalur}

Dengan pendekatan analisis jalur, yakni kombinasi regresi variabel bebas terhadap variabel tak bebas (Kinerja guru) dan adanya hubungan kausalitas antar variabel bebas $\left(\mathrm{r}_{\mathrm{xixj}}\right)$, dinyatakan berikut ini:

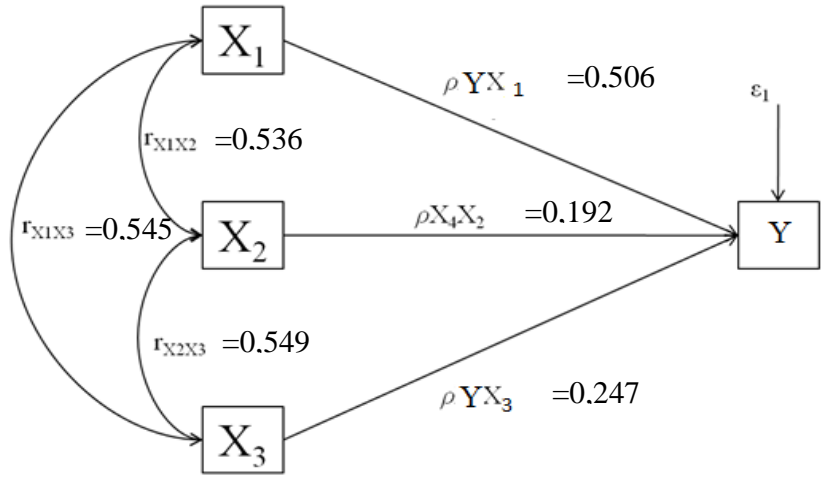

Gambar 3 Diagram Jalur Penelitian 


\section{e. Uji Model}

Untuk dapat menyatakan bahwa hasil hitung koefisien korelasi $\left(\mathrm{r}_{\mathrm{xi}, \mathrm{x} \mathrm{j}}\right)$ yang merupakan korelasi hubungan kausalitas antar variabel eksogen, dan signifikansi koefisien jalur yang merupakan koefisien pengaruh variabel eksogen terhadap endogen, dilakukan pengujiannya.

Hipotesis 1: " Kepemimpinan berpengaruh terhadap Kinerja".

Hasil pengujian menunjukkan harga $t_{\text {hitung }}$ sebesar 5,881 yang lebih besar dari t-tabel $=1,24$, dan nilai ini signifikans pada taraf uji $0,000 \%$. Sehingga Ho ditolak dan Ha diterima artinya koefisien jalur Kepemimpinan berpengaruh terhadap Kinerja personil Polri pada kantor Polres Pidie Jaya.

Hipotesis 2: "Kepemimpinan berpengaruh terhadap Kinerja".

Hasil pengujian menunjukkan harga $t_{\text {hitung }}$ sebesar 2,220. Dengan demikian $t_{\text {hitung }}>t_{\text {tabel }}(2,220>1,24)$, dan nilai ini juga signifikansi dari hasil olahan data pada taraf uji 0,029\%. Sehingga Ho ditolak dan Ha diterima artinya koefisien jalur variabel Budaya organisasi terhadap Kinerja. dapat dinyatakan signifikan pada taraf signifikan $\alpha=0,05$. Dengan demikian dapat dinyatakan bahwa terdapat pengaruh secara signifikan Budaya organisasi berpengaruh terhadap Kinerja personil Polri pada kantor Polres Pidie Jaya.

Hipotesis 3: " Motivasi kerja berpengaruh terhadap Kinerja".

Hasil pengujian menunjukkan harga $t_{\text {hitung }}$ sebesar 2,838 Dengan demikian $t_{\text {hitung }}>t_{\text {tabel }}(2,838>1,24)$. Sehingga Ha diterima artinya koefisien jalur variabel Motivasi kerja berpengaruh berpengaruh terhadap Kinerja personil Polri pada kantor Polres Pidie Jaya.

e. Hasil Analisis Pengaruh variabel dan Pembahasan

1). Analisis Pengaruh Variabel Kepemimpinan terhadap Kinerja Personil

\begin{tabular}{|l|c|c|c|c|}
\hline \multicolumn{2}{|r|}{$\begin{array}{c}\text { Variabel } \\
\text { Kepemimpinan }\end{array}$} & \multicolumn{2}{c|}{ Melalui } & \multirow{2}{*}{ Jumlah } \\
\cline { 3 - 5 } & $25,60 \%$ & & Motivasi kerja & \\
\hline Pengaruh langsung $\left(\rho_{\mathrm{yx} 1}=0,506\right)$ & & $(0,506)(0,536)(0,192)(100 \%)$ & $(0,506)(0,545)(0,247)(100 \%)$ & $12,02 \%$ \\
\hline Pengaruh tidak langsung & & $5,21 \%$ & $6,81 \%$ & $37,62 \%$ \\
\hline Pengaruh total & $25,60 \%$ & & & $25,60 \%$ \\
\hline
\end{tabular}

Berdasarkan pengaruh langsung dan tidak langsung, maka dapat dihitung besarnya total pengaruh Kepemimpinan terhadap Kinerja, yakni : 37,62\%.

Hal ini senada dari penelitian Indra Syaputra dan Yasri (2015) dan Artina,dkk (2014) bahwa Kepemimpinan berpengaruh positif dan signifikan terhadap disiplin personil.

2). Analisis Pengaruh Variabel Budaya organisasi terhadap Kinerja Personil

\begin{tabular}{|l|c|c|c|c|}
\hline \multicolumn{2}{|r|}{$\begin{array}{r}\text { Variabel } \\
\text { Budaya organisasi }\end{array}$} & \multicolumn{2}{c|}{ Melalui } & \multirow{2}{*}{ Jumlah } \\
\cline { 3 - 5 } & $3,69 \%$ & & Motivasi kerja & \\
\hline Pengaruh langsung $\left(\rho_{\mathrm{yx} 2}=0,192\right)$ & & $(0,192)(0,536)(0,506)(100 \%)$ & $(0,192)(0,549)(0,247)(100 \%)$ & $7,81 \%$ \\
\hline Pengaruh tidak langsung & $3,69 \%$ & $5,21 \%$ & $2,60 \%$ & $11,50 \%$ \\
\hline Pengaruh total & & & & $3,69 \%$ \\
\hline
\end{tabular}

Maka besarnya total pengaruh Budaya organisasi terhadap Kinerja personil, yakni: 11,50\%.

Hasil yang sama juga didapatkan Solikin (2019) yang meneliti kinerja anggota Polsek Trimurjo Polres Lampung Tengah. Peran kepemimpinan memberikan kontribusi terhadap kinerja anggota Polsek Trimurjo sebesar $47,10 \%$. 
3). Analisis Pengaruh Variabel Motivasi kerja terhadap Kinerja personil

\begin{tabular}{|l|c|c|c|c|}
\hline & Variabel & \multicolumn{2}{|c|}{ Melalui } & \multirow{2}{*}{ Jumlah } \\
\cline { 3 - 4 } & Motivasi kerja & Kepemimpinan & Budaya organisasi & \\
\hline Pengaruh langsung $\left(\rho_{\mathrm{yx} 2}=0,247\right)$ & $6,10 \%$ & & & $6,10 \%$ \\
\hline Pengaruh tidak langsung & & $(0,247)(0,545)(0,506)(100 \%)$ & $(0,247)(0,549)(0,192)(100 \%)$ & $9,41 \%$ \\
\hline Pengaruh total & $6,10 \%$ & $6,81 \%$ & $2,60 \%$ & $15,51 \%$ \\
\hline
\end{tabular}

Maka besarnya total pengaruh Motivasi kerja terhadap Kinerja, yakni : 15,51\%.

Hal yang sama diperoleh Saharazad (2016) dimana hasil uji statistik, motivasi kerja berpengaruh signifikan terhadap kinerja anggota Kepolisian di Polsek Cakung Jakarta Timur.

4). Analisis Pengaruh Variabel Kepemimpinan, Budaya organisasi, dan Motivasi kerja terhadap Kinerja Personil Polres Pidie Jaya

Merujuk dari hasil model jalur yakni: $Y=0,506 X_{1}+0,192 X_{2}+0,247 X_{3}$

(Y= Kinerja personil, X1 = Kepemimpinan, X2 = Budaya organisasi, X3 = Motivasi kerja)

Maka dapat dijelaskan bahwa koefisien jalur Koefisien Kepemimpinan bernilai positif $(0,506)$ artinya apabila Kepemimpinan diupayakan baik akan dapat mendukung kinerja personil dengan rata-rata kenaikan 50,6\%. Juga adanya budaya organisasi yang mendukung dapat meningkatkan kinerja personil dengan koefisien bernilai positif $(0,192)$ artinya rata-rata kenaiakan nya adalah $19,2 \%$. Dan koefisien jalur Motivasi kerja bernilai positif $(0,247)$ artinya apabila tingkat motivasi kerja personil meningkat akan menaikkan rata-rata 24,7 persen dari kinerja personil.

Selain menguji koefisien regresi, penelitian ini juga menguji koefisien korelasi (R) dan koefisien determinasi $\left(\mathrm{R}^{2}\right)$, menurut Ghozali (2012) koefisien korelasi dan determinasi mengukur peran variabel bebas pada variabel terikat, yang dapat dilihat dari tabel berikut:

Tabel 4. Koeisien Korelasi Simultan

\begin{tabular}{|c|c|c|c|}
\hline $\mathrm{R}$ & $\mathrm{R}$ Square & Adjusted R Square & Std. Error of Estimate \\
\hline $.803^{\mathrm{a}}$ & .645 & .631 & 2.566063 \\
\hline
\end{tabular}

Hasil analisis koefisien korelasi $R$ sebesar 0,803 menjelaskan hubungan antara variabel kepemimpinan, budaya organisasi dan motivasi kerja terhadap kinerja memiliki keeratan yang tinggi, dan berhubungan secara linier, dengan derajat hubungannya sebesar 0,803 .

Kontribusi faktor Kepemimpinan, Budaya organisasi dan motivasi kerja terhadap Kinerja personil Polri pada Kantor Polres Pidie Jaya sebesar 64,5\%. Sementara sisanya (nilai residu) dari peran variabel yang tidak diteliti sebesar 35,5\%. Faktor-faktor lain secara teoritis seperti fasilitas kerja, konpensasi, pengembangan karir, dan Pendidikan.

\section{Simpulan (Conclusion)}

Berdasarkan hasil penelitian dapat disimpulkan beberapa uraian untuk menjawab rumusan masalah sesuai dengan penelitian, adalah sebagai berikut:

\section{1). Hasil Penelitian secara Deskriptif}

Berdasarkan respon dari personil kepolisian yang diteliti tingkat Kepemimpinan yang dirasakan terhadap apa yang diharapkan personil Polri pada kantor Polres Pidie Jaya, dinilai oleh personil sudah baik, mencapai 79,56 persen dari harapan. Sementara penilaian tentang aspek budaya organisasi, termasuk cukup baik dalam mendukung kinerja personil. Skor penilaian personil atas budaya organisasi di kalangan kantor mencapai 73,48 \% dan Dari penilaian tingkat motivasi kerja personil mencapai $76 \%$, dan hal ini termasuk cukup baik. Sedangkan tingkat Kinerja sudah mencapai kategori cukup baik, yakni mencapai $74,03 \%$.

\section{2). Hasil Penelitian Kuantitatif dengan Analisis Jalur}

Berdasarkan analisis secara kuantitatif, menggunakan pendekatan analisis jalur, diperoleh hasil: 
a) Terdapat Pengaruh yang signifikans aspek Kepemimpinan terhadap Kinerja personil Polri pada kantor Polres Pidie Jaya (Y), baik pengaruh langsung ataupun pengaruh tidak langsung karena adanya hubungan antar variabel yang diteliti, yakni sebesar 37,62 persen.

b) Terdapat pengaruh langsung faktor Budaya organisasi, ataupun pengaruh tidak langsung karena adanya hubungan kausal Budaya organisasi dengan Kepemimpinan dan Motivasi kerja terhadap Kinerja personil Polri pada kantor Polres Pidie Jaya, yakni 11,50 persen

c) Terdapat pengaruh yang signifikans aspek Motivasi kerja terhadap Kinerja Personil Polri pada kantor Polres Pidie Jaya, yakni 15,51 persen

d) Besarnya pengaruh dari variabel Kepemimpinan, Budaya organisasi dan Motivasi kerja terhadap kinerja personil sebesar $64,5 \%$. Sementara sisanya (nilai residu) dari peran variabel yang tidak diteliti sebesar 35,5\%. Nilai residu tersebut menujukkan bahwa terdapat faktor-faktor lain yang dapat mempengaruhi variabel Kinerja personil Polri pada kantor Polres Pidie Jaya, seperti fasilitas kerja, konpensasi, pengembangan karir, Pendidikan, dan lain-lain.

\section{DAFTAR PUSTAKA (References)}

1) Artina, HB Isyandi dan Sri Indarti. 2014, Pengaruh Kepemimpinan, Budaya Kerja, Lingkungan Kerja Terhadap Disiplin Kerja dan Kinerja Personil Polda Riau, Jurnal Tepak Manajemen Bisnis, Vol.VI No.2.

2) Arikunto, S, 2010. Prosedur Peneltian Suatu Pendekatan Praktik. Jakarta: Rineka Cipta

3) Anoraga, Pandji, 2012, Manajemen Bisnis, Rineka Cipta, Jakarta.

4) Indra Syaputra dan Yasri. 2015, Pengaruh Fungsi Kepemimpinan, Lingkungan Kerja, Dan Motivasi Kerja Terhadap Kinerja Personil Polisi Di Kantor Kepolisian Resort Pasaman Barat, Jurnal Riset Manajemen Bisnis dan Publik, Vol 3 No 3

5) Jauch, L.R. dan Glueck, W.R. 1997, Manajemen Strategis dan Kebijakan. Perusahaan, Edisi IV, Erlangga, Jakarta.

6) Kreitner, Robert and Kinicki, Angelo. 2010. Organizational Behavior, Ninth Edition. New York: McGraw-Hill/Irwin.

7) Mangkunegara, Anwar Prabu. 2011. Manajemen Sumber Daya Perusahaan. PT. Remaja Rosdakarya. Bandung

8) Mas'ud, Fuad, 2004, Survai Diagnosis Organisasional, Badan Penerbit. Universitas Diponegoro, Semarang

9) Marwan Hamid, Ibrahim Sufi, Win Konadi, dan Yusrizal Akmal, 2019. Analisis Jalur Dan Aplikasi Spss Versi 25, Edisi Pertama Sefa Bumi Persada, Medan.

10) Hariandja, Marihat Tua Efendi, 2002, Manajemen Sumber. Daya Manusia, Grasindo, Jakarta:

11) M. Yusuf, 2015. Pengaruh Diklat Dan Disiplin Kerja Terhadap Produktivitas Kerja Pegawai Pada Dinas Kehutanan Dan Perkebunan Kabupaten Bireuen, Jurnal Kebangsaan, Vol.4 No.7, Januari 2015.

12) Nirwana, A.B. 2014. Perbandingan Model Regresi Cox Menggunakan Time-Dependent Variable dan Stratified Proportional Hazard untuk Mengatasi Nonproportional Hazard. Jurnal Statistik FMIPA Universitas Brawijaya 2(1): 69-72

13) Nova dan Megasari Gusandra Saragih, 2016, The Analyze Effect of the Motivation, Competence, Task Attractions and Situational Factors Of Performance Sekretariat Daerah Employees Pemerintah Kabupaten Bireuen, Jurnal Kebangsaan, Vol.5 No.9

14) Ogbonna, Emmanuel dan Harris Lloyd C, 2000. Leadership Style, Organizational Culture and Performance: Empirical Evidence From UK Companies. The International Journal Of Human Resources Management.

15) Samsudin, 2005. Manajemen Sumber Daya Manusia, Pustaka Setia.

16) Sani, Achmad dan Maharani, Vivin. 2012. The Impact of Transformational Leadership and Organizational Commitment on Job Performance with the among Lecturers of Faculty in the Islamic Maulana Malik Ibrahim Malang University: The Mediating Effects of Organizational Citizenship Behaviour. International Journal of Academic Research Part B.

17) Salanova, Marisa, Lorente, Laura, Chambel Maria J., and Martinez, Isabel M. 2011. Linking Transformational Leadership to Nurses'extra-role Performance: The Mediating Role of Self-efficacy and Work Engagement. Journal of Advanced Nursing.

18) Syazhashah Putra Bahrum, Inggrid Wahyuni Sinaga, 2015. Pengaruh Kepemimpinan Dan Motivasi Kerja Terhadap Kinerja Pegawai (Studi Pada Pegawai Lembaga Dewan Kawasan Perdagangan Bebas Pelabuhan Bebas Batam Bintan Karimun), Jurnal Akuntansi, Ekonomi dan Manajemen Bisnis, Vol. 3(2) $135-141$ 
19) Shahzad et. al. 2012. Impact of Organizational Culture on Organizational Performance: An Overview. Interdisciplinary Journal of Contemporary Research in Business 3, (9). 975-985.

20) Sembiring, Masana. 2012. Budaya dan Kinerja Organisasi. Fokusmedia.

21) Siagian, Sondang P, 2003. Teori dan Praktek Kepemimpinan. PT Rineka Cipta. Jakarta

22) Sugiyono, D. 2014. Metode Penelitian Kuantitatif Kualitatif dan R\&D. Bandung: CV Alfabeta.

23) Sujarweni dan Endrayanto. 2012, Statistika untuk Penelitian. Yogyakarta: Graha Ilmu

24) Solikin, 2019. Pengaruh Peran Kepemimpinan Dan Budaya Kerja Terhadap Kinerja Anggota Kepolisian Pada Polsek Trimurjo Polres Lampung Tengah. Jurnal Simplex Volume 2, No 1, April 2019

25) Sujarweni, V dan Poly Endrayanto. 2012. Statistika untuk Penelitian. Yogyakarta:

26) Suryo, Bhikku Dharma. 2010. Pengaruh Gaya Kepemimpinan Transformasional, Budaya Organisasi dan Inovasi terhadap Kinerja. Jurnal Aplikasi Manajemen, Volume 8. Tahun 2010.

27) Taba Iskandar, 2004. Pengaruh Kepemimpinan Dan Budaya Organisasi Terhadap Motivasi Kerja Karyawan Pada Kantor Badan Otorita Batam. Thesis, Universitas Airlangga.

28) Walumbwa, Fred O. and Hartnell, Chad A. 2010. Understanding Transformational LeadershipEmployee Performance Links: The Role of Relational Identification and Self-efficacy. Journal of Occupational and Organisasional Psychology.

29) Win Konadi dan Faisal Jalal, 2019. Pengaruh Motivasi Kerja Dan Lingkungan Kerja Terhadap Kinerja Pegawai di Sekretariat DPRK Bireuen, Jurnal Kebangsaan, Vol.8 No.15, edisi Januari-Juni 2019 